\title{
IEC 61850 Communication Protocol with the Protection and Control Numerical Relays for Optimum Substation Automation System
}

\author{
Adel A. Elbaset, Yehia Sayed Mohamed and Amer Nasr A. Elghaffar*
}

Electrical Engineering Department, Minia University, 61517, Minia, Egypt

Received 8 May 2018; Accepted 12 July 2019

\begin{abstract}
The substation automation technologies are considered as the highlights points to innovation with the researchers and electric companies, which resulted in the development of numerous protocols and standards. The high voltage substation control system is considered as one of the main challenges to reach the optimum operating system. In the past, it's difficult to re-install the protection or control relay by a different manufacturer, to avoid the log-off the communication with the substation control system. The International Electro-Technical Commission (IEC) 61850 protocol is a new technique for the communication and remote control of the Substation Automation System (SAS). IEC 61850 protocol is a more flexible communication system for control, fast for operation, high accuracy measurements and interoperability between many different manufactures Intelligent Electronic Devices (IEDs). The Generic Object-Oriented Substation Event (GOOSE) is the light important function in IEC 61850 protocol to represent a status function from the remote IEDs to operates in the local IEDs. This paper discusses the substation automation system control depending on the IEC 61850 communication protocol for the optimum automation system. The simulation in this paper has been validated with 220.0 $\mathrm{kV}$ transmission line and $220.0 / 66.0 \mathrm{kV}$ power transformer to discusses the actual operating system for control, alarms, status, and measurements.
\end{abstract}

Keywords: IEC 61850, Protection system, SAS, GOOSE and High voltage.

\section{Introduction}

The complete power system is classified to generation, transmission, and distribution to be easy for controlling and for saving the reliable and stability system. The utility grid is operates depending on the generation system that can be different ways as conventional generation or renewable or compound between renewable and conventional system. Hence, its important to search for the new technologies to save the system in reliable and under controlling to reach the satisfaction of the consumers. The links points in the grid are called the substations that can convert the voltage to the required value through the transformation and/or the routing of energy. The controlling for switching in the substations are uses the multi-bays to be easy for controlling, every bay contains the circuit breakers, disconnector switches and the earther switches, that can operate in input or output feeding. [1]. The control system of the high voltage substations is considered as the most important task to safe the system and to accelerate the normalization system after abnormal condition [2]. The power system extension and the increase of the renewable energy with the distributed generation are required to more accurate and flexible control system to absorb any additional signals and fast to analyze the power system disturbances [3]. Hence, it's important to search for the best substation automation way to increase the reliability in the online conventional substation to cover and absorb the old system as a subsidiary system in parallel mode. The old substation communication was depending on the telephonic

*E-mail address: amernasr70@yahoo.com

ISSN: 1791-2377 @ 2020 School of Science, HUU. All rights reserved.

doi:10.25103/jestr.132.01 switching system, which required human participation, that more running cost [4]. The Supervisory Control and Data Acquisition System (SCADA) is referring to the combination of telemetry and data acquisition, SCADA encompasses the collecting of the information via a Remote Terminal Unit (RTU), transferring it back to the central site, carrying out any necessary analysis and control and then displaying the information to a number of operator screens or displays [2-4] . The International Electro-Technical Commission (IEC) 61850 is a global standard for substation automation to provide interoperable and standardized communication [5] . IEC 61850 has emerged as a de facto standard for substation automation in the utility world over. IEC 61850 semantic interoperability is representing the operating system with the benefit of sub-systems among multi-vendor protection and control devices, which is not applicable to cover by the UCA 2.0 communication system [5]. In addition, the IEC 61850 communication system is a highly accurate protocol to send the commands from the control centre to the required equipment into the substation, receiving the feedback status and allows accurate time synchronized disturbance recorder. According to the IEC 61850 protocol is process by the bus Ethernet Local Area Network (LAN) to be facilitated the communication of time-critical messages, such as Generic Object-Oriented Substation Event (GOOSE) and raw data sampled values, within the allowable time [6]. This paper discusses the architecture design of the IEC 61850 protocol to be used with the Substation Automation System (SAS). Also, the simulation in this paper has been validated by using the facilities of the IEC 61850 communication standard with the $220.0 \mathrm{kV}$ overhead line and $220.0 / 66.0 \mathrm{kV}$ power transformer for allowing accurate measurements, safe operation, and fast fault analysis. 
Adel A. Elbaset, Yehia Sayed Mohamed and Amer Nasr A. Elghaffar/

Journal of Engineering Science and Technology Review 13 (2) (2020)1 - 12

\section{IEC 61850 Architectures}

A typical Substation Automation System (SAS) is consists of one or several master stations communicating with thousands of Remote Terminal Units (RTUs) to provide data acquisition and control functionality [ $7-\underline{8}]$. However, the power system should be continuously under controlling and supervising with high accuracy to send the operation commands [9-10]. IEC 61850 communication protocol is considering the higher step to be used with the Substation Configuration Language (SCD) to generate security measures concerning the firewall, Intrusion Detection System (IDS) and Intrusion Prevention System (IPS) [11]. IEC 61850 communication standard can be added the ability to support multiple logical devices within a single physical device, this support contains data to understand the new extension in the model of a multi-device Gateway. In addition to the use of separate data concentrators, Originating Point Codes (OPC) technology also offers a way to incorporate simple Gateway functionality into a substation SCADA system. IEC 61850 protocol is enables data from all IEDs to modify or added functions [12]. At the process level, analog data of the primary plants in the switchyard is converted to digital signals using merger units and is communicated using local area network (LAN) to the protection and control equipment at the bay level [13-14]. Human Machine Interface (HMI) presents a translator address numbers to the definition text. To be used to allow the trending and diagnostic data by the link with the SCADA databases system and software [15-18]. HMI can manage information such as record maintenance system, logistic. The substation automation by IEC 61850 has been expanded to the whole power system including communications between substations and other inter-domain communications [19]. The IEC 61850 communication stander architecture component can be justified to the following two items.

\subsection{Remote Terminal Unit (RTU)}

In the overall scheme, SAS and communication topologies play an important role in a digital substation, based on IEC 61850. Substation automation can be loosely interpreted in three essential purposes: control, status, recording, communication and protection functions [20]. The RTU can supervise the equipment status open/close by the Bay Control Unit (BCU). BCU can use an input, output module for status, commands and current and voltage coils for the measurements. The fiber optic cable is the link between the BCU and the RTU SCADA master. The RTU panels are supplied by $220 \mathrm{AC}$ voltage and operate by $48 \mathrm{~V} \mathrm{DC}$, also the components having the power supply card, memory communication card, and processor [21-23]. The Communication system is requiring to updated because it's not attainable to achieve with the SAS when communication is failing. The Remote Terminal Unit (RTU) is a significant element of the SCADA system in power applications to execute the commands from the SCADA system [21]. The RTU operates as a relation interface between the IEDs and the SCADA master, it supports the supervisors by accurate and fast real-time operation and monitoring of analog and digital data. In addition, the RTU operates by depending on the Analog Input (AI), Digital Input (DI), Communication Interface (CI) and Digital Output (DO). AI and DI are responsible electronic cards for monitoring the measurement elements in the substation. CI module has a serial receiver, decoder, Inner-timer, Data and Time Logger (DTL) and coding and transmitter component which receives and decodes commands coming from the control centre and transmit the reformed data again to the centre [22]. The digital inputs are used to indicate the substation equipment status and auxiliaries. The digital outputs in RTU are used to send the order command to the circuit breaker, isolator switches, and trip relay reset commands [22-23]. Fig. 1 shows the RTU operation with the SAS IEC 61850 communication system.

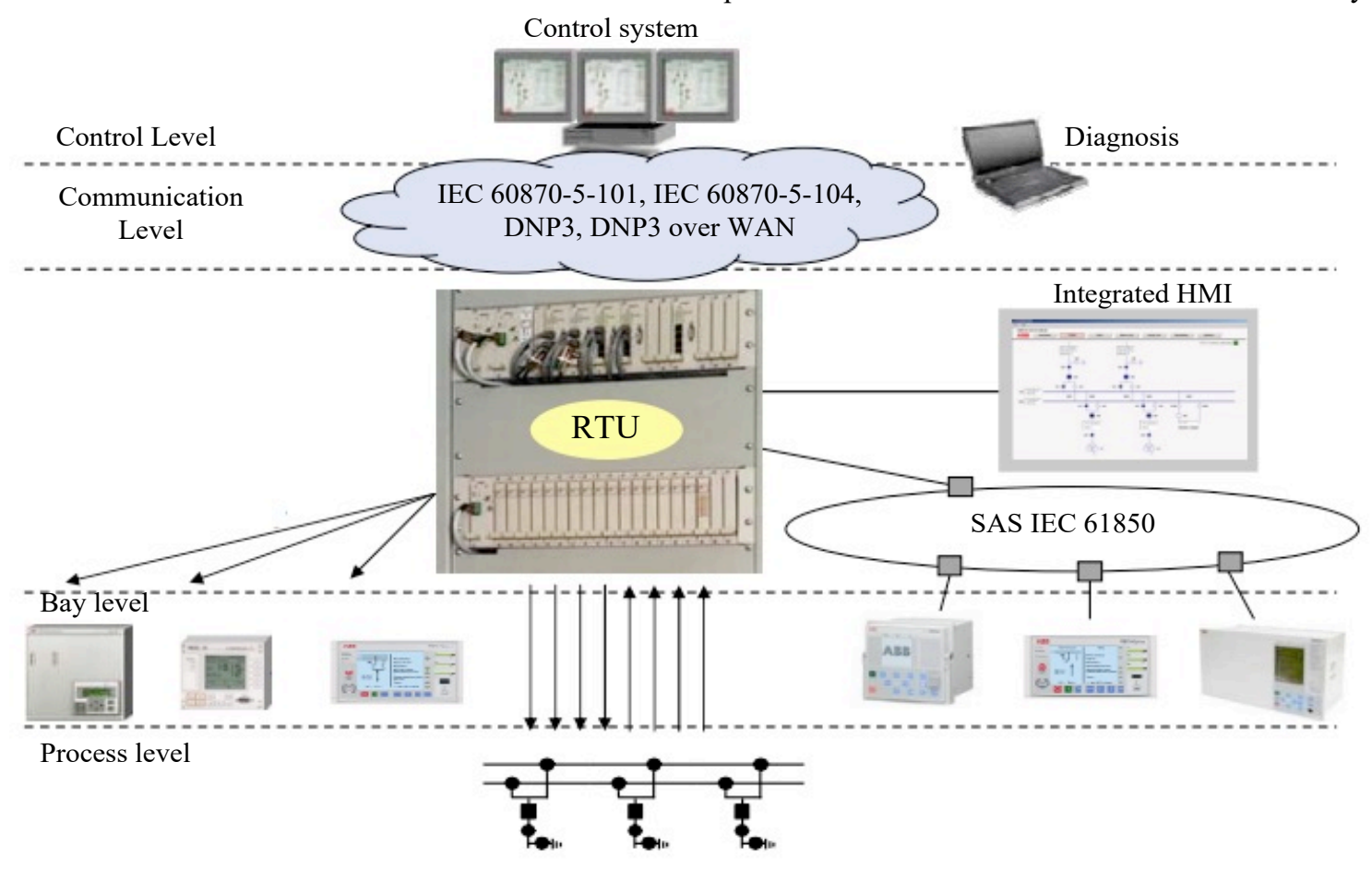

Fig. 1. RTU operation with SAS IEC 61850 protocol [ABB-Design].

\subsection{Gateway}

It's very important to keep the high voltage substation devices online continuously under controlling and supervising to ensure a reliable and safe operation system. Several SAS applications require additional synchronization services to work properly. The data collected by a distributed 
Adel A. Elbaset, Yehia Sayed Mohamed and Amer Nasr A. Elghaffar/

Journal of Engineering Science and Technology Review 13 (2) (2020)1 - 12

measurement system are affected by communication and synchronization uncertainty [24]. Fault recorders and fault locators are examples of applications benefitting from accurate time synchronization. The IEC 61850 provides for different time synchronization classes, each of them specifies the required accuracy. The SCADA gateway is a windows application to be used by the System Integrators and Utilities (SIU) to collect data from Originating Point Codes (OPC), IEC 61850, IEC 608705, DNP3, or Modbus (MB) Server/Slave devices and then supplies this data to other control systems supporting OPC. The Gateway functions used to translate between the protocols. The Data Concentrator (DC) is a communication gateway that collects metering, states, event and fault data from IEDs [25]. The Gateway has two communication interfaces, i.e., the serial interface and the Ethernet interface. The Gateway receives data from the Distributed Energy Resources (DER) controller by referring the serial link with the proprietary protocol and transmit these data to the monitoring system in the control centre. As long as the mapping data between the proprietary protocol and the IEC 61850 data model is possible, the proposed system architecture can be extended to any other protocol, DNP, Modbus, and so on. IEC 61850 Gateway should be a universal product, but not specific to one legacy IED type. A welldesigned IEC 61850 Gateway should have the following characteristics: supply IEC 61850 standard compliant service, flexibly adapted the legacy bay IEDs of different manufacturers to comply with IEC 61850 standards, universal equipment, and low maintenance cost and high reliability. which consist of four main modules: IED configuration tool, protocol converter, IEC 61850 real-time database and IEC 61850 services module [26]. The gateway sends report messages to the substation computer monitoring when data received from a DER controller is different from what the gateway has or within the pre-defined period [27]. The data gateway system comprises three major components. First management centre which is responsible for controlling the system. Second is Energy Database Server which is used to save the energy consumption data. The last is Data Acquisition Gateway (data gateway for short) which is responsible for collecting and transferring energy data. The core of the system is located in the management centre, and the key device is a data gateway which is located in the data acquisition site [28]. Due to hardware limitation, the gateway can send report messages every $10 \mathrm{msec}$ on a minimum, translating to 100 report messages per second.

\section{IEC 61850 Protocol Operation Strategies}

The IEC 61850 protocols aim to reduce the data management with a bandwidth that does not present any issues. IEC 61850 communication system is a faster protocol for operation and stable communication, it can be operated as a complete control system inside the high voltage substation by remote control centre by depending on the SAS [29-30]. SAS is referring to the required control tasks from IEDs in the substation, for example, monitoring, control and protection the high voltage equipment. The copper wires inside the substation are created a very complex network which developed and treated by using the LAN related to Ethernet connections. The LAN connection is the faster for collecting data, security, easy for maintaining and installing with the SAS IEC 61850 protocol to produce and consume signals, which are usually communicated by thousands of wires between the primary equipment and protection, monitoring control and automation devices. IEC 61850 [31-32]. IEC 61850 communication standard can be added the ability to support multiple logical devices within a single physical device, this support contains data to understand the new extension in the model of a multi-device Gateway. In addition to the use of separate data concentrators, Originating Point Codes (OPC) technology also offers a way to incorporate simple Gateway functionality into a substation SCADA system. IEC 61850 enables data from all IEDs to modify or added functions [12]. At the process level, analog data of the primary plants in the switchyard is converted to digital signals using merger units and is communicated using local area network (LAN) to the protection and control equipment at the bay level. Fig. 2 shows the architecture connections inside the substations using IEC 61850 with the protection IEDs. GOOSE is a very flexible high-priority reliable mechanism for fast transmission of substation events such as trip commands, interlocking and critical status indications. GOOSE messages are used to replace the hardwired control signal exchange between IEDs for interlocking, protection purpose, and sensitive missions that are time critical and require high reliability. The main contributions of IEC 61850 protocol with the SAS in the high voltage substations can be justified to the following four items.

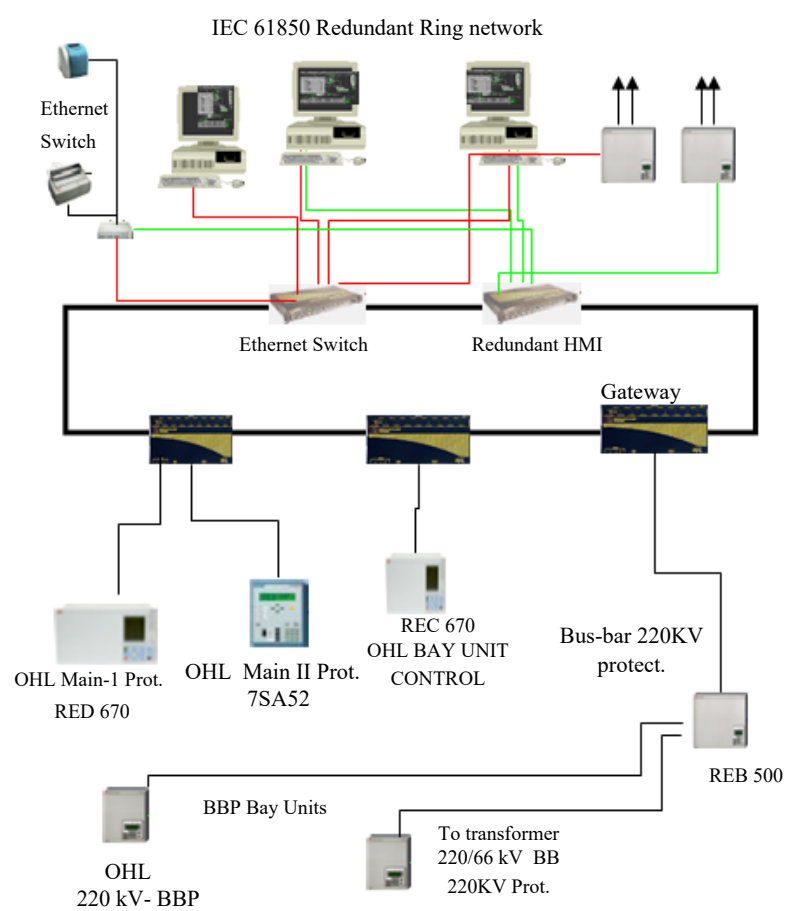

Fig. 2. Interlock control signals by IEC 61850 communication system with the protection IEDs.

\subsection{Time synchronization}

The time synchronization between the protection IEDs and the SAS is considered very high importance to send the commands or equipment status (open/close) without delay time. In addition, the recording relays trip actions or alarms must be inaccurate time synchronization to help the supervisor in the control system for fast analyzing the disturbance. The previous automation protocols have a gap between the actual status and the communication records for equipment status and any abnormal condition in the substation, as the Modbus protocol is depending on the scan for all system IED step by step to send any variant status to the control centre. The accurate time synchronization is considered one of the challenges for control and automates the high voltage substation. The communications between the 
Adel A. Elbaset, Yehia Sayed Mohamed and Amer Nasr A. Elghaffar/

Journal of Engineering Science and Technology Review 13 (2) (2020)1 - 12

control centre and the protection IEDs is required to recover the supervising relays within time tolerance not up to $400 \mathrm{~ms}$ traffic interruption in the case of a link failure. IEC 61850 protocol is allowing for high reliable accurate time, this contribution can support the protection IEDs differential function with the busbar protection, which depends on the summation bays current [33]. The IEC 61850 communication standards are working by retrieving the different changes in the IDs which communicate with all relays in the same time, which consider the time synchronization in range of millisecond in LAN by operating with the Network Time Protocol (NTP) and Simple Network Time Protocol (SNTP). The radio signals and Global Position System (GPS) can be used also to implement time synchronization, which consists of a theoretically possible to achieve high precision synchronization with the GPS [34]. Finally, the communication profile is used in relation conjunction with the IEC 61850 specifies objects which contains a time attribute to ensure the system homogeneity and action validity by the GPS modules with horizontal communication capability

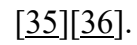

\subsection{Interoperability}

It's not practical to design and manufacture completely substation with one protection IEDs vendor, also, it's not applicable to maintain the substation in the future or to add a new extension with the same IEDs vendor. A communication system protocol has been allowed to ensure the exchange of critical information, e.g., operation, commands, indications feedback, and load measurements [15][36]. By this case, the substation automation will block to operates with the new IED relays or the replaced system [16]. IEC 61850 communication stander can solve this shortage to control for many different IED vendors. The communication with a multi-IEDs vendor can be called Interoperability, which represents a high requirement contribution function to be covered by IEC 61850 protocol. The interoperability for IEDs by different suppliers has the following shorten aspects, IEDs shall be able to connect to a common bus protocol system (this known as syntax), IEDs shall understand to provide data to other IEDs and also be creating information from other devices (this knowing as semantics) and IEDs shall be understood to grouping with other devices at a concentration action. For example, the busbar protection IED trip command (this knowing as: distributed functions) [17-18], which totally not completely covered by another protocols for examples, Distributed Network Protocol (DNP), UCA 3.0, Modbus, and PROFIBUS, as well as other proprietary protocols with custom communication links will found [18] [37]. Hence, using the different manufacturer IEDs which provided interoperability with no constraints on the system structure and data exchange is considered a highly important facility to uses the IEC 61850 for a communication system with the SAS.

\subsection{GOOSE message}

The concept of the smart digital substation is based on the use of intelligent primary equipment and networked secondary devices, to share digital information and realize distributed protection and control functions. In high voltage substations, there are multi pieces of equipment in one circuit bay or power transformer bay that contains circuit breakers, isolator switches, and earth switches [38]. To send the operation command, the system must require to check the safe operation without an interlock. The interlocks are a feedback status to supervise all bay component, for example, to operate for open or close the circuit breaker with service condition, it must be no connection earth switch in the present bay. But, at the interlock required to check another status from another bay units, so, it will lead to multi-connection to the control present IEDs from all bay units and the present IEDs can't absorb all substation connections. For example, to close the busbar earth switch, it must check the open status for all busbar isolator switches. Fig. $\underline{\mathbf{3}}$ shows the interlock required conditions for safe to operate the busbar earth switch by check all busbar disconnector bays. Regarding the required from SAS to allow attaching the required status by the protection or control IEDs, using the IEC 61850 communication protocol with utilizing the GOOSE message can configure the interlocking table without the wiring connection [39-40]. GOOSE is a very flexible high-priority reliable mechanism for fast transmission of substation events such as trip commands, interlocking and critical status indications. GOOSE messages are used to replace the hardwired control signal exchange between IEDs for interlocking, protection purpose, and sensitive missions that are time critical and require high reliability. GOOSE messages also contain information that allows the receiving device to know the status change [41]. For example, in Fig. $\underline{\mathbf{3}}$ can retrieve all busbar disconnector status to the control IEDs for the busbar earth switch by the IEC 61850 GOOSE function. Therefore, the main important to uses the IEC 61850 for the GOOSE message times to prevent any false operation, also, can obtain the time delay of the event generated after triggering to the subscribe function near to zero seconds [42]. In GOOSE communications, the address number for all binary inputs feedback from the equipment status is the main parameter to verify the required equipment status. The GOOSE message is operating by the telegrams that usually sent through a multicast mechanism, the sender does not define the destination IEDs. Each IED was depending on the implemented configuration, decides whether to subscribe to a GOOSE message or not. If an IED receives a GOOSE, which was not programmed to subscribe, it simply ignores the message to avoid the false operation [43]. Finally, the high voltage substation can be classified and easy to control with interlock design performed in different IEDs, the communication with each other is available by IEC 61850 protocol. By comparing the security of protection schemes with conventional technology and numerical technology by use GOOSE message, which can offer the possibility to increase the security of the protection schemes by the ability to use the GOOSE message to build the software interlock between two equipment. Fig. $\underline{4}$ shows the operation logic to use the GOOSE messages function allowed by the IEC 61850 communication system between different protection IEDs. However, the IEC 61850 communication protocol is easy to support the operation interlock system between the power transformer high side and low voltage side to prevent the wrong operation [44].

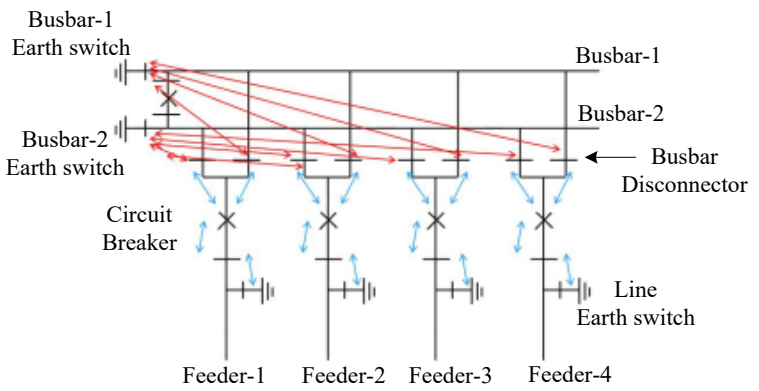

Fig. 3. Operation interlock for busbar disconnectors units with the busbar earth switch. 
Adel A. Elbaset, Yehia Sayed Mohamed and Amer Nasr A. Elghaffar/

Journal of Engineering Science and Technology Review 13 (2) (2020)1 - 12

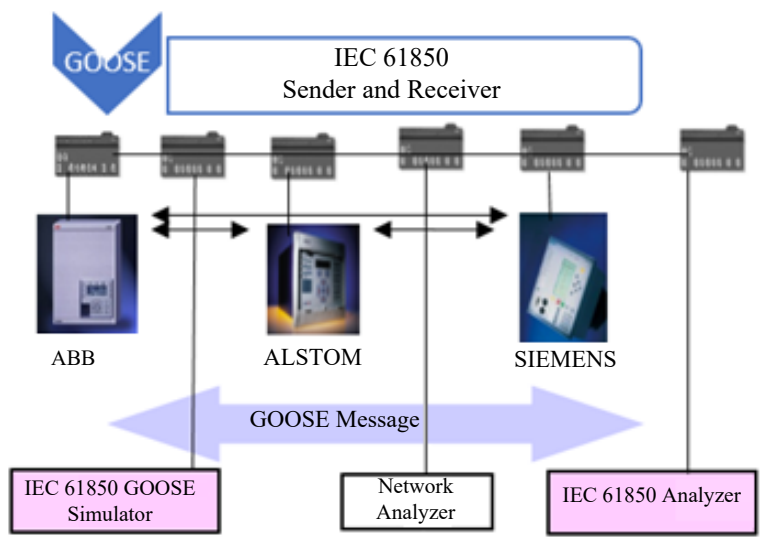

Fig. 4. IEC 61850 communication system GOOSE messages between protection IEDs.

\subsection{IEC 61850 for aided trip scheme}

There are some abnormal conditions and electrical faults occur in the power system due to the collapse of the insulation between the living conductor with the earth, the overloads, mechanical damage, lightning, or switching which cause variation in the voltage, etc. Hence, it's important to use the protection system which considers one of the main parts in the high voltage substation [45]. The conventional substations secondary wiring has been improved in a digital substation using fiber optic cable connection to IEDs due to technological advancement [46] [47]. The digital numerical protection devices are the high step technology at comparing with the electromechanical or electrostatic devices, which have the availability to communicate with the protocols system as Modbus or UCA.2.0 communication system and IEC 61850 protocol [45]-[뇨-49]. The main contributions of the numerical relays are the accurate sensitivity, digital showing the instantaneous measurements, fault recorder function and the protection IEDs has the function to be used with IEC 61850 protocol for sending and receiving data. In order to provide distance protection between two substations, IEC 61850 protocol can uses with the protection numerical relay for accelerating the protection scheme depending on the fiber optic cable to be linked between the two remote and local protection IEDs [50]. The timing requirement of the protection scheme to operate during a fault being very critical, such as interlocking and blocking, the protection IEDs must act quickly within 4-ms, which can cover by the IEC 61850 stander [51]. The fiber cable is considered as a very high data transmission rate. The acceleration facility is contributing to isolate the line instantaneously at the fault happen in the transmission line [52-53]. This facility important at the line fault near one side which the remote IED protection relay calculate the fault impedance in the zone two boundaries, which will send the trip order after $200 \mathrm{~ms}$ to $500 \mathrm{~ms}$ delay time. IEC 61850 communication scheme will accelerate the isolation fault to be an instantaneous trip in both sides by adjusting the zone 1 to transport the signal to the remote IED which configure to trip at carrier receive with starting zone 2 distance protection [50]. Fig. $\underline{\mathbf{5}}$ shows the connection between two substations for the permissive acceleration scheme. However, the IEC 61850 communication protocol can to uses with the differential protection relay to cover the differential function, where, the transfer time is the sum of the processing times at the sender and receiver and the network transmission time. The protection system was not adversely affected by synchronizing errors significantly larger than the standards permit, suggesting that requirements may be overly conservative [44][54]. Fig. $\underline{\mathbf{6}}$ shows the actual configuration for transmitting and receiving signal with the distance added trip function through fiber connection by the MICOM distance relay as an example of the protection IED. Hence, by using the IEC 61850 protocol with the protection system can enhance the power system stability and the reliability by supervising the substation alarms with significant time-saving in fault clearance.

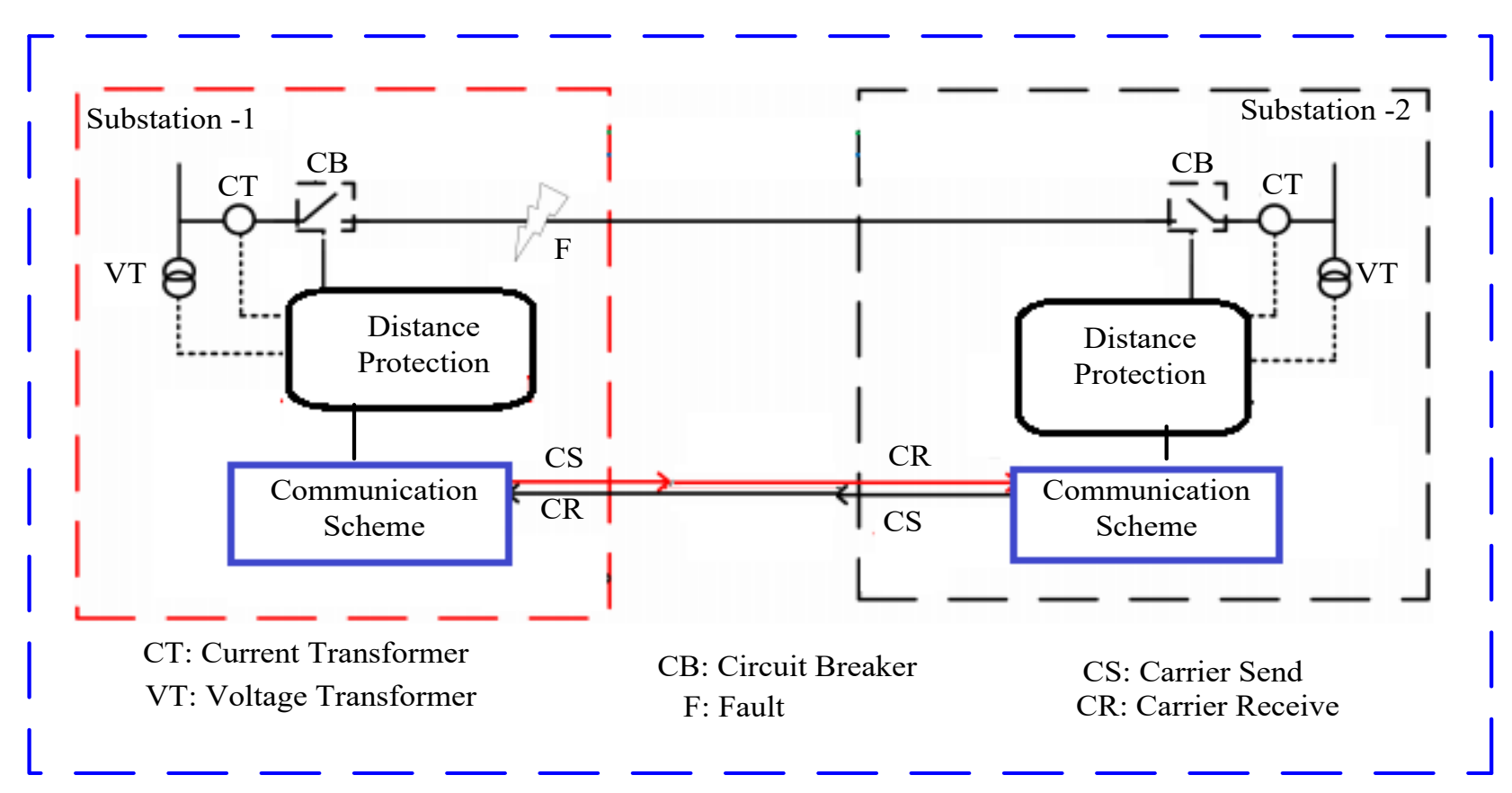

Fig. 5. The accelerating permissive scheme between two IEDs using IEC 61850 communication system. 

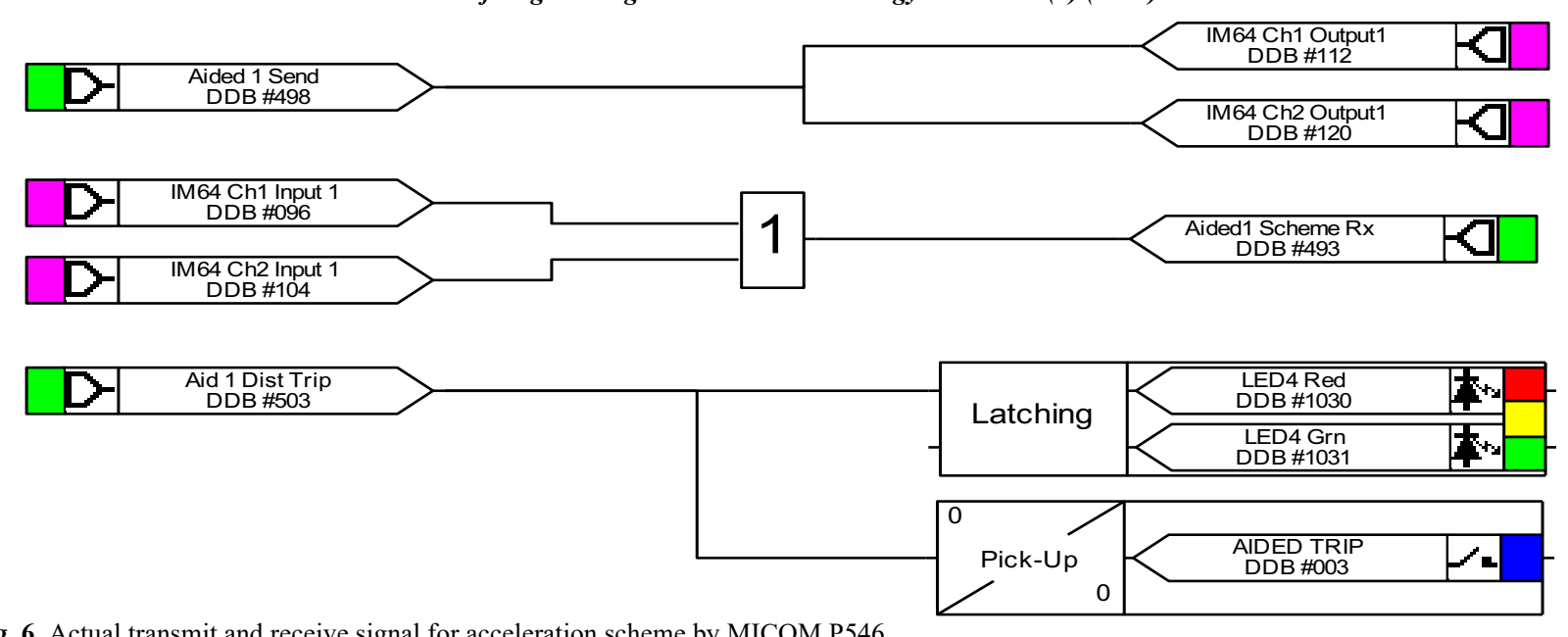

Fig. 6. Actual transmit and receive signal for acceleration scheme by MICOM P546.

\section{IEC 61850 Transmitting Data to Control Centre}

The main reason of developing IEC 61850 was to create an international standard that will ease the communication between substation devices using Logical Nodes (LN) and data classes to address the issues regarding the interoperability and interchangeability, which instead of a configured IED description (CID) file. IEC 61850 protocol is starting by translating the protection function into the relay to the Manufacturing Message Specification (MMS) data that able to uses for the roots in addressing data and to report digital statuses and simulated alarm inputs. Fig. 7 shows the mapping of the multi-function protection relay SEL-411L into the protection logic to the MMS data which known in this relay type by "PSV**", where "**" means the MMS number which can introduce in the SAS configuration with IEC 61850 as the actual operation function. Also, fig.8 shows the mapping of MICOM-P546 multi-function protection relay, which translating the MMS as a virtual output into the relay that translating in the SAS configuration to the programmed protection function. Table (1) shows the text of the protection function in fg.7 and fig. 8. Once the protocols are created the next step is to map them to the data models and services of the standard, the HMI inside the substation can show the unlimited alarms and status. In another hand, to decrease the alarms in the control centre which shows a lot of substation alarms, it's possible by the IEC 61850 to compress the matched alarms to one address as shown in table (3) for the National Control Centre (NCC) address. The ring links between the HV substations are depending on the Ethernet cables to transmit the digital code address to reach the control centre throw two main and backup channels.

Protection Free-Form Logic Settings: PROTSEL1 - PROTSEL

1 PSV24 : = Z1PT OR Z1GT $\#$ Z1 TRIP

2 PSV $25:=$ : $22 P T$ OR Z2GT) \# Z2 TRIP

3 PSV26: $:$ (Z3PT OR Z3GT) \#Z3 TRIP

4 PSV $40:=870 P$ AND PCT010 AND (PHASE_A OR 87LA) \# DIFF OPTD PHASE $~$

5 PSV $41:=870 P$ AND PCT01Q AND (PHASE_B OR 87LB) \# DIFF OPTD PHASE Y

Fig. 7. Converting the protection function to the MMS data object into SEL-411L IED.

\section{IEC 61850 Simulation}

This part of IEC 61850 specifies standard techniques for testing of conformance of implementations, as well as specific measurement techniques to be applied when declaring performance parameters. IEC 61850 communication protocol is allowing to operates with SAS for supervising the events and the load measurements in the substation, this information is recorded in order the duration time in the Human Machine Interface (HMI) with SAS engineering in control room. The power system automation is the performance of automatically controlling and supervising the power system by the automated method within computers and IEDs. This automation is consisting of three important design specifically data acquisition, power system supervision and power systems control, all working in a coordinated automatic procedure [55]. Modbus is one of the methods for communication systems to be used with high voltage substations. Modbus system provides parsing messages, it is can use to monitor with supervising and the program to IEDs, it operates by using PCs and powered Human Machine Interface (HMI) [ 56- $\underline{57]}$. Modbus information is different from the IEC 61850 protocol, which is a linear plane [58]. The connection with Modbus can be via RS 232, 10/100 Base-F connection and 10/100 Base-T connection. By comparing the Modbus protocol with IEC 61850 protocol, it found the Modbus protocol does not allow events sequence duration, the events without indication time and Modbus does not provide lists report. Data acquisition describes collecting data in the form of measured analog current or voltage values or open/close status of contact points [ $\underline{56}-\underline{58}]$. Power system automation is carried out by the worker and maintenance engineers through this acquired data either at a remote site represented by computer displays and the command messages sent to the control IEDs to close or open the required equipment.

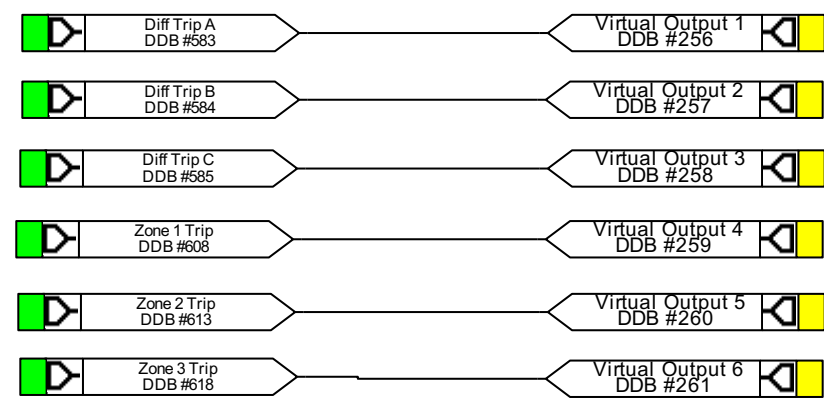

Fig. 8. Converting the protection function to the MMS data object into MICOM P546. 
Adel A. Elbaset, Yehia Sayed Mohamed and Amer Nasr A. Elghaffar/

Journal of Engineering Science and Technology Review 13 (2) (2020)1 - 12

Table 1. The text of the protection function in fg.7. and fig. 8 .

\begin{tabular}{|c|c|c|}
\hline No. & Abbreviation & Protection function text \\
\hline 1 & Z1PT & [SEL-411L] Distance protection first zone phase-phase trip \\
\hline 2 & Z1GT & [SEL-411L] Distance protection first zone phase-ground trip \\
\hline 3 & $\mathrm{Z} 2 \mathrm{PT}$ & [SEL-411L] Distance protection second zone phase-phase trip \\
\hline 4 & Z2GT & [SEL-411L] Distance protection second zone phase-ground trip \\
\hline 5 & Z3PT & [SEL-411L] Distance protection third zone phase-phase trip \\
\hline 6 & Z3GT & [SEL-411L] Distance protection third zone phase-ground trip \\
\hline 7 & $87 \mathrm{OP}$ & [SEL-411L] Line differential trip \\
\hline 8 & $87 \mathrm{LA}$ & [SEL-411L] Line differential trip phase-A \\
\hline 9 & $87 \mathrm{LB}$ & [SEL-411L] Line differential trip phase-B \\
\hline 10 & $87 \mathrm{LC}$ & [SEL-411L] Line differential trip phase-C \\
\hline 11 & Diff Trip A & [MICOM-P546] Line differential trip phase-A \\
\hline 12 & Diff Trip B & [MICOM-P546] Line differential trip phase-B \\
\hline 13 & Diff Trip C & [MICOM-P546] Line differential trip phase-C \\
\hline 14 & Zone 1 Trip & [MICOM-P546] General distance protection first zone trip \\
\hline 15 & Zone 2 Trip & [MICOM-P546] General distance protection second zone trip \\
\hline 16 & Zone 3 Trip & [MICOM-P546] General distance protection third zone trip \\
\hline
\end{tabular}

\subsection{Monitoring system status and measurements}

The SAS measurements are the real-time supervisory monitoring system to shows the feedback measured data by the BCU or protection IEDs relay. The monitoring unit records the measurements and state indications with time stamps. Most of the measurement data are used for customer power quality monitoring. The following quantities can be measured and calculated (currents, voltages, pressures, temperatures, contacts and etc.) [59-60]. IEC 61850 can retrieve the measurements from a different vendor in the same substation to shown in locally HMI and transmit to the remote-control centre as shown in fig. $\underline{9}$ for the sample SAS feeder measurements and the indication status. Also, fig. $\underline{9}$ shows the yellow lock indication for the operation interlock to know the release interlock for safe and correct operation. Where, during the line in service if the disconnector switch opened it will fail due to the design of the circuit breaker to operate for close or open under load condition to damp the spark. Moreover, after open the circuit breaker the disconnector switch interlock will release to able to open. Fig. $\underline{10}$ shows the sample substation Single Line Diagram (SLD) for busbar connection with the grid through OHTL and uses the step-down power transformer $220 / 66.0 \mathrm{kV}$. The measurements simulation can be illustrated by the secondary injection with the BCU by using the secondary injection kit Freja 300 to test the SAS system as shown in table (2), where the test system uses for OHTL $220 \mathrm{kV}$ at different values, where, the current transformer ratio setting is (2000/1 A), and the voltage transformer ratio is ((220/sqrt (3) $\mathrm{kV} / 110 / \mathrm{sqr}$ (3) V). The high voltage substation is connected with the grid through the Over-Head Transmission Line (OHTL). The step up/down transformer is used to control the voltage as required value [61]. The busbar is connected with the OHTL or the transformer by the bay unit, the bay unit is containing the connection equipment as the Circuit Breaker (CB), Disconnectors Switch (DS) and Earth Switch (ES). The substation equipment status (Open/Close) can be collected and transmitted by the input module card for the BCU IEDs. The BCU binary output card is used to send the commands to the CB, DS, and ES. Table ( $\underline{3}$ ) shows the sending high voltage equipment status by using IEC 61850 protocol to the national control centre for the illustrated example in fig. 10.

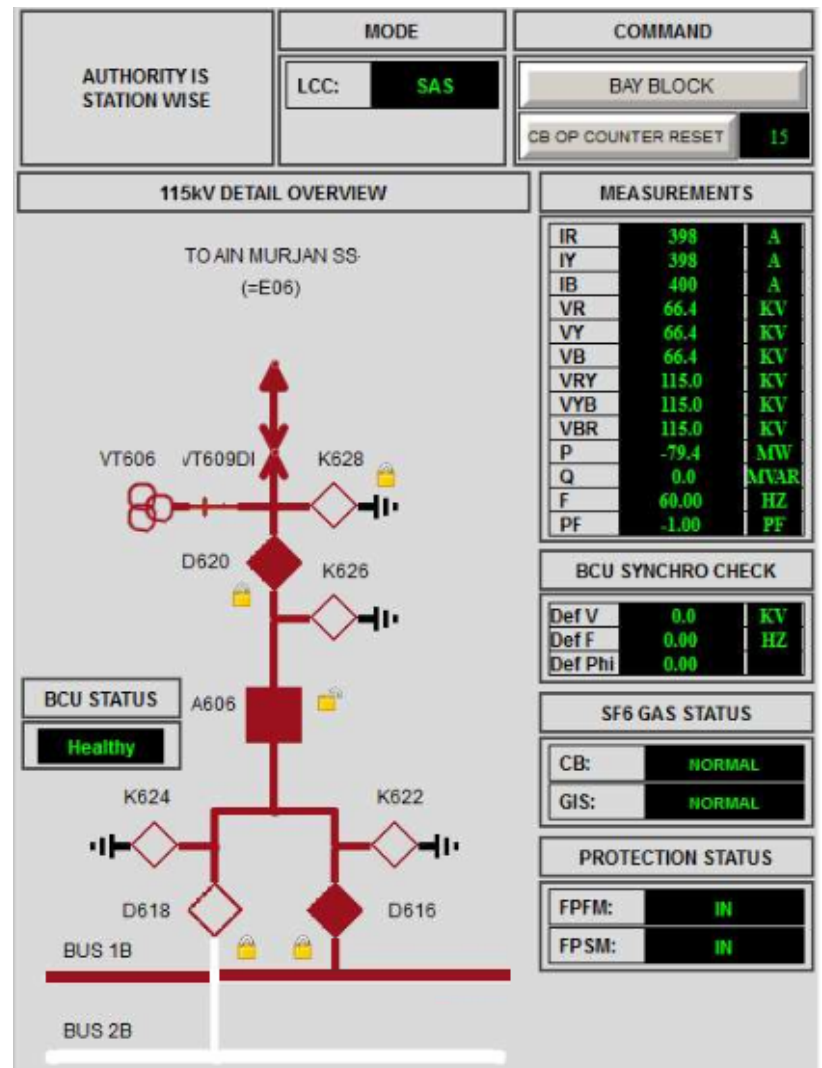

Fig. 9. Sample SAS feeder measurements and indication status.

Table 2. Actual metering current at different injection values.

\begin{tabular}{|c|c|c|c|c|c|c|c|c|}
\hline \multirow{2}{*}{ Required } & \multirow{2}{*}{$\begin{array}{l}\text { Injection } \\
\text { secondary } \\
\text { current }\end{array}$} & \multirow{2}{*}{$\begin{array}{c}\text { Expect. } \\
\text { Value }\end{array}$} & \multicolumn{3}{|c|}{ Value in (HMI) Inside Control Room } & \multicolumn{3}{|c|}{ Value in National Control Centre } \\
\hline & & & $\mathbf{R}$ & $\mathbf{Y}$ & B & $\mathbf{R}$ & $\mathbf{Y}$ & B \\
\hline \multirow{3}{*}{$\begin{array}{c}\text { Phases } \\
\text { Current } \\
\text { (A) }\end{array}$} & $50 \%$ & 1000 & 997.1 & 997.4 & 998.8 & 997.1 & 997.5 & 998.9 \\
\hline & $100 \%$ & 2000 & 1996.5 & 1997.8 & 1998.8 & 1996.4 & 1997.7 & 1998.8 \\
\hline & $50 \%=28.86$ & 110 & 109.992 & 110.011 & 109.995 & 110.010 & 110.016 & 110.015 \\
\hline
\end{tabular}


Adel A. Elbaset, Yehia Sayed Mohamed and Amer Nasr A. Elghaffar/

Journal of Engineering Science and Technology Review 13 (2) (2020)1 - 12

\begin{tabular}{c|c|c|c|c|c|c|c|c}
\hline $\begin{array}{c}\text { Phases } \\
\begin{array}{c}\text { Voltage } \\
(\mathrm{kV})\end{array}\end{array}$ & $100 \%=57.73$ & 220 & 220.001 & 220.005 & 220.004 & 219.995 & 220.001 & 220.006 \\
\hline
\end{tabular}

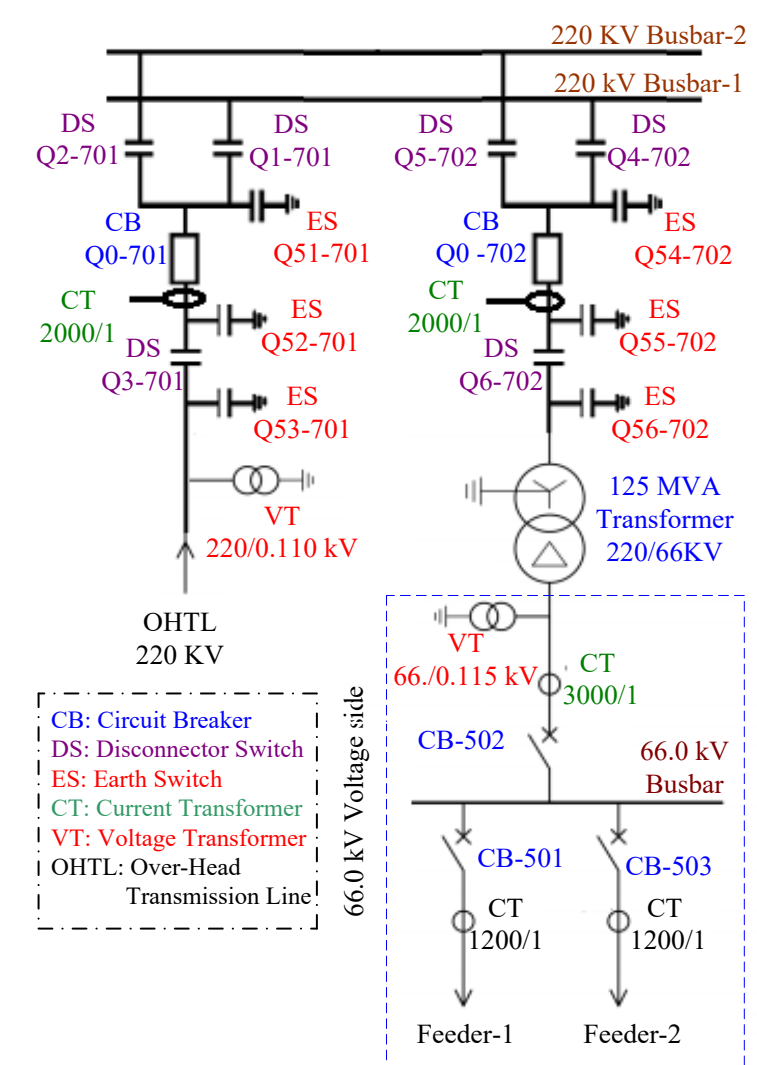

Fig. 10. SLD sample substation $220.0 / 66.0 \mathrm{kV}$.

\subsection{IEC 61850 for event analysis}

One of the important roles to uses the IEC 61850 communication system with the high voltage substation, is to analyze the abnormal or faults condition in the substation. The SCADA system is required to capital investment, but a good
SCADA/DMA system implemented in a phased manner brings returns in a shorter period, all data are available in realtime and historical data in the archive for planning and other applications of utility [16]. However, the IEC 61850 communication standard can retrieve the events from different IEDs in one system. The software architecture and the reference devices reliability make possible to perform a broad range of measurement types, by generating the desired waveform signal and recording it during desired time intervals [59-62]. The SAS configuration by the IEC 61850 uses the event function logic name to translate to the HMI address which is direct can translate again to the full text about the event in the HMI, for example fig. 11 shows the IEC 61850 configuration text for 7SA522-SIEMENS protection distance IED to use the fault serial name which is (PROT/PTRC2/OP) for the (Distance protection general trip). And after attending the operation manpower to report the fault, by using the IEC 61850, it's easy to communicate with all IEDs from the HMI SAS engineering to retrieve the disturbance recorder from the protection IED as shown in fig. 12. Where, it shows the fault secondary current has been increased to 1.5 Ampere in $\mathrm{PH}-\mathrm{A}$, and other phases $\mathrm{PH}-\mathrm{B}$ and $\mathrm{PH}-\mathrm{C}$ the current is between 0.002Ampere and 0.003A. low. By the same case, the IEC 61850 can retrieve the disturbance recorder from different vendor by the HMI engineering into the substation as shown in fig. $\underline{\mathbf{1 3}}$ for MICOM P546, which shows the trip time and the types of faults in the transmission line. These serial names can show for all abnormal conditions in the HMI inside the substation, but at the limited text in the control system, by the IEC 61850 protocol, it can collect the multi-signals for some faults to one group. For example, the distance Zone 1 trip, Distance Zone 2 trip and Distance Zone 3 trip can collect to one signal in the control system which is line distance trip, also for overcurrent trip can merge to one signal as showing in the table (ㅁ).

Table 3. High voltage equipment status for MAGHAGHA-1 OHTL $220.0 \mathrm{kV}$.

\begin{tabular}{|c|c|c|c|c|c|c|}
\hline \multirow[b]{2}{*}{$\begin{array}{l}\text { Sr. } \\
\text { no }\end{array}$} & \multicolumn{2}{|c|}{ BCU location } & \multicolumn{2}{|c|}{ SAS HMI internal substation } & \multicolumn{2}{|c|}{ Status in control centre } \\
\hline & Source & $\begin{array}{l}\text { BCU } \\
\text { Status }\end{array}$ & SAS Text & क्षे & $\begin{array}{l}0 \\
z\end{array}$ & SCADA TEXT \\
\hline 1 & \multirow{2}{*}{$\begin{array}{c}\text { Q0 } \\
\text { MAGHAGHA-1 } \\
\text { OHTL 220kV }\end{array}$} & OPEN & $\begin{array}{l}\text { Circuit Breaker Q0 } \\
\text { OPEN }\end{array}$ & OPEN & \multirow[t]{2}{*}{2030} & $\begin{array}{l}\text { MAGHAGHA-1 Circuit Breaker } \\
\text { Q0 Open }\end{array}$ \\
\hline 2 & & CLOSE & $\begin{array}{l}\text { Circuit Breaker Q0 } \\
\text { CLOSE }\end{array}$ & CLOSE & & $\begin{array}{l}\text { MAGHAGHA-1 Circuit } \\
\text { Breaker Q0 Close }\end{array}$ \\
\hline 3 & \multirow{2}{*}{$\begin{array}{c}\text { Q1 } \\
\text { MAGHAGHA-1 } \\
\text { OHTL 220kV }\end{array}$} & OPEN & $\begin{array}{l}\text { Busbar-1 Disconnector } \\
\text { Q1 OPEN }\end{array}$ & OPEN & \multirow[t]{2}{*}{2031} & $\begin{array}{l}\text { MAGHAGHA-1 OHTL BB-1 } \\
\text { Dis-connector Q1 Open }\end{array}$ \\
\hline 4 & & CLOSE & $\begin{array}{l}\text { Busbar-1 Disconnector } \\
\text { Q1 CLOSE }\end{array}$ & CLOSE & & $\begin{array}{l}\text { MAGHAGHA-1 OHTL BB-1 } \\
\text { Dis-connector Q1 Close }\end{array}$ \\
\hline 5 & \multirow{2}{*}{$\begin{array}{c}\text { Q2 } \\
\text { MAGHAGHA-1 } \\
\text { OHTL 220kV }\end{array}$} & OPEN & $\begin{array}{l}\text { Busbar-1 Disconnector } \\
\text { Q2 OPEN }\end{array}$ & OPEN & \multirow{2}{*}{2032} & $\begin{array}{l}\text { MAGHAGHA-1 OHTL BB-2 } \\
\text { Dis-connector Q2 Open }\end{array}$ \\
\hline 6 & & CLOSE & $\begin{array}{l}\text { Busbar-1 Disconnector } \\
\text { Q2 CLOSE }\end{array}$ & CLOSE & & $\begin{array}{l}\text { MAGHAGHA-1 OHTL BB-2 } \\
\text { Dis-connector Q2 Close }\end{array}$ \\
\hline 7 & \multirow{2}{*}{$\begin{array}{c}\text { Q3 } \\
\text { MAGHAGHA-1 } \\
\text { OHTL 220kV }\end{array}$} & OPEN & $\begin{array}{l}\text { Busbar-1 Disconnector } \\
\text { Q3 OPEN }\end{array}$ & OPEN & \multirow{2}{*}{2033} & $\begin{array}{l}\text { MAGHAGHA-1 OHTL Line } \\
\text { Dis-connector Q3 Open }\end{array}$ \\
\hline 8 & & CLOSE & $\begin{array}{l}\text { Busbar-1 Disconnector } \\
\text { Q3 CLOSE }\end{array}$ & CLOSE & & $\begin{array}{l}\text { MAGHAGHA-1 OHTL Line } \\
\text { Dis-connector Q3 Close }\end{array}$ \\
\hline 9 & Q51 & OPEN & $\begin{array}{l}\text { Maintenance Earth } \\
\text { Switch Q51 OPEN }\end{array}$ & OPEN & 2034 & $\begin{array}{l}\text { MAGHAGHA-1 OHTL } \\
\text { Maintenance ES - Q51 Open }\end{array}$ \\
\hline
\end{tabular}




\begin{tabular}{|c|c|c|c|c|c|c|}
\hline 10 & $\begin{array}{l}\text { MAGHAGHA-1 } \\
\text { OHTL 220kV }\end{array}$ & CLOSE & $\begin{array}{l}\text { Maintenance Earth } \\
\text { Switch Q51 CLOSE }\end{array}$ & CLOSE & & $\begin{array}{l}\text { MAGHAGHA-1 OHTL } \\
\text { Maintenance ES - Q51 Close }\end{array}$ \\
\hline 11 & \multirow{2}{*}{$\begin{array}{c}\text { Q52 } \\
\text { MAGHAGHA-1 } \\
\text { OHTL 220kV }\end{array}$} & OPEN & $\begin{array}{l}\text { Maintenance Earth } \\
\text { Switch Q52 OPEN }\end{array}$ & OPEN & \multirow{2}{*}{2035} & $\begin{array}{l}\text { MAGHAGHA-1 OHTL } \\
\text { Maintenance ES - Q52 Open }\end{array}$ \\
\hline 12 & & CLOSE & $\begin{array}{l}\text { Maintenance Earth } \\
\text { Switch Q52 CLOSE }\end{array}$ & CLOSE & & $\begin{array}{l}\text { MAGHAGHA-1 OHTL } \\
\text { Maintenance ES - Q52 Close }\end{array}$ \\
\hline 13 & \multirow{2}{*}{$\begin{array}{c}\text { Q53 } \\
\text { MAGHAGHA-1 } \\
\text { OHTL 220kV }\end{array}$} & OPEN & $\begin{array}{l}\text { Maintenance Earth } \\
\text { Switch Q53 OPEN }\end{array}$ & OPEN & \multirow{2}{*}{2035} & $\begin{array}{l}\text { MAGHAGHA-1 OHTL } \\
\text { Maintenance ES - Q53 Open }\end{array}$ \\
\hline 14 & & CLOSE & $\begin{array}{l}\text { Maintenance Earth } \\
\text { Switch Q53 CLOSE }\end{array}$ & CLOSE & & $\begin{array}{l}\text { MAGHAGHA-1 OHTL } \\
\text { Maintenance ES - Q53 Close }\end{array}$ \\
\hline
\end{tabular}

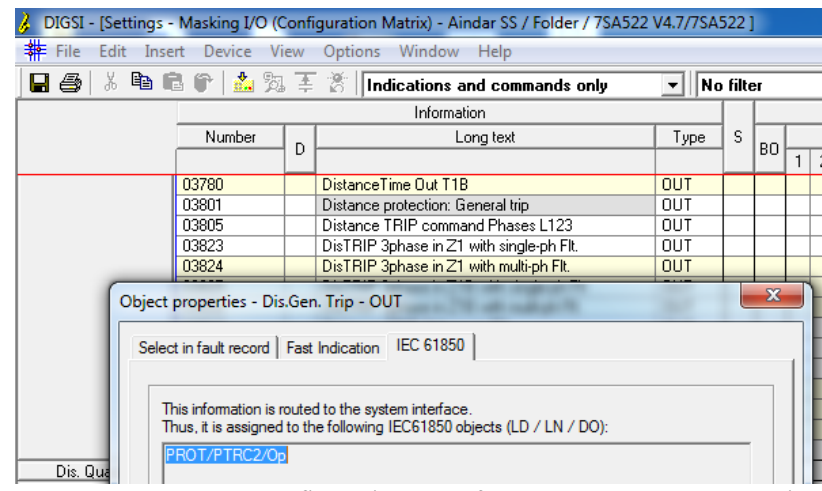

Fig. 11. IEC 61850 configuration text for 7SD SIEMENS protection distance IED
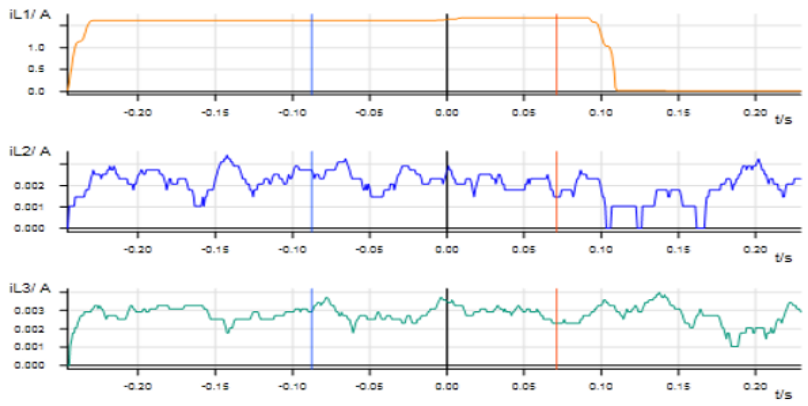

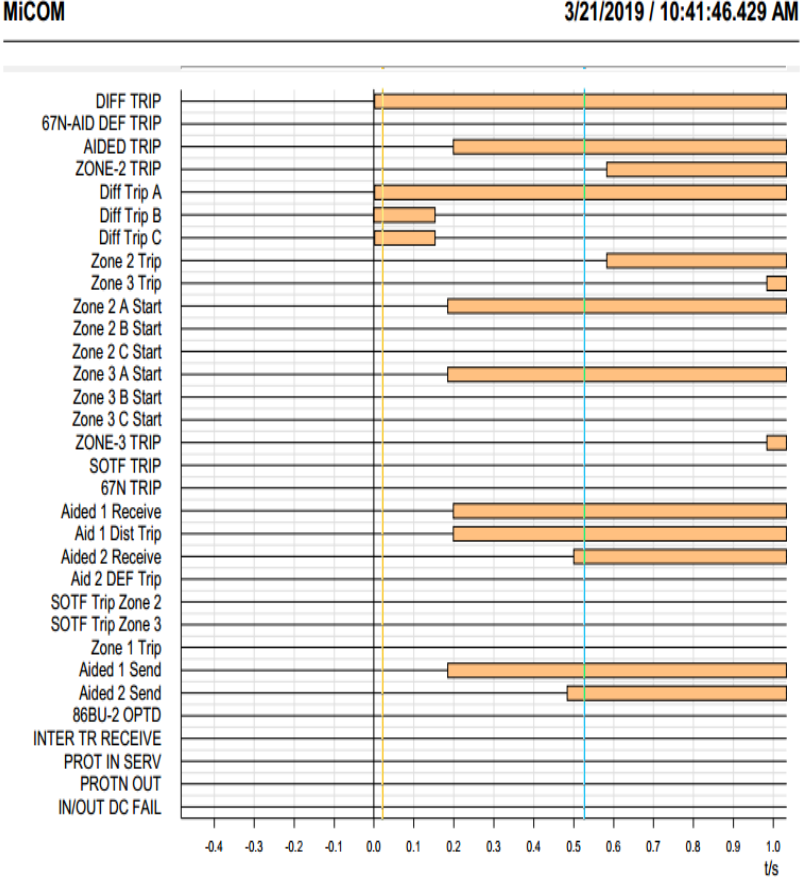

Fig. 13. Fault analysis supervised by SAS using IEC 61850 with MICOM-P546 protection IED.

Fig. 12. Disturbance recorder supervised by SAS IEC 61850 for

SIEMENS protection IED.

Table 4. Samples transmitting faults by IEC 61850 for OHTL protection relay.

\begin{tabular}{|c|c|c|c|c|}
\hline \multirow[b]{2}{*}{ Sr. no } & Panel & \multirow[b]{2}{*}{ SOE, HMI (SAS Text) } & \multicolumn{2}{|r|}{ SCADA Masters } \\
\hline & Source & & $\begin{array}{l}\text { SCADA } \\
\text { Address }\end{array}$ & SCADA Text \\
\hline 1 & Prot. Main-1 & $\begin{array}{c}\text { MAGHAGHA-1 -220KV- OHTL - O/C Prot. } \\
\text { L1 Operated }\end{array}$ & & \\
\hline 2 & Prot. Main-1 & $\begin{array}{c}\text { MAGHAGHA-1 -220KV - OHTL - O/C Prot. } \\
\text { L2 Operated }\end{array}$ & 1106 & MAGHAGHA-1 -220KV - \\
\hline 3 & Prot. Main-1 & $\begin{array}{c}\text { MAGHAGHA-1 -220KV - OHTL - O/C Prot. } \\
\text { L3 Operated }\end{array}$ & 1106 & OHTL -O/C-E/F Prot. Operated \\
\hline 4 & Prot. Main-1 & $\begin{array}{c}\text { MAGHAGHA-1 }-220 \mathrm{KV}-\mathrm{OHTL}-\mathrm{E} / \mathrm{F} \text { Prot. } \\
\text { Operated }\end{array}$ & & \\
\hline 5 & Prot. Main-1 & $\begin{array}{c}\text { MAGHAGHA-1 -220KV - OHTL - } 21 \text { Dist. } \\
\text { Prot. Zone-1 Trip }\end{array}$ & & \\
\hline 6 & Prot. Main-1 & $\begin{array}{c}\text { MAGHAGHA-1 -220KV - OHTL - } 21 \text { Dist. } \\
\text { Prot. Zone-2 Trip }\end{array}$ & 1107 & $\begin{array}{l}\text { MAGHAGHA-1 -220KV - } \\
\text { OHTL - Dist. Prot. Operated }\end{array}$ \\
\hline 7 & Prot. Main-1 & $\begin{array}{c}\text { MAGHAGHA-1 -220KV - OHTL - } 21 \text { Dist. } \\
\text { Prot. Zone-3 Trip }\end{array}$ & & \\
\hline
\end{tabular}

\section{Conclusion}

Nowadays, the electrical power system has become more complex due to extension and increasing of power demand. Hence, it's important to save the stable system from faults or any abnormal conditions. By using the suitable control system for enhancing the power system quality to save the system in the safe operation and control, also to support the operation and maintenance team to normalize the system in very low time after interruption or any abnormal condition. Protection, control, and automation of the electric power grid have experienced a rapid development in the last few decades; migrating towards fully digital Substation Automation Systems (SASs). This paper investigated the scope of IEC 
61850 communication protocol to covers the SAS with highly accurate time synchronization. The advantage of using the IEC 61850 protocol is the unlimited signal can to uses to cover all system status and alarms which is important to absorb the system extension in the future. In addition, all protection schemes within the substation require zero recovery time in the event of a fault. In other words, the circuit must provide zero recovery time to bounce back into active normal mode after suffering a failure. With the advancement in IEC 61850 technology, it is possible to achieve these objectives to uses the accelerating trip scheme function in the IEDs. This study contributed the benefits of using the IEC 61850 protocol with SAS as; allowing a single physical device to operate from the Gateway by operator manpower, from the national control centre and allows to communicates with multiple devices to provide a high accuracy real-time standard representation of data with SCADA. Moreover, IEC 61850 protocol can provide benefits for distributed applications within electrical substations as it permits reducing conventional copper wiring and optimizing the total installed cost by minimizing the efforts related to engineering, installation, commissioning, and maintenance. The simulation in this paper has been implemented by the secondary injection for the protection and control IED, the simulation aims to introduce the number of non-supervised alarms and functions will be reduced to zero, a high accurate event recorder time and increases the availability of the system. Finally, from this paper it is important to recommend the high voltage substation designers to consider the IEC 61850 protocol for the substation automation system, to absorb the system extension in the future, fast to analyze the disturbance and enhancing the power system quality.

\section{Acknowledgment}

The authors wish to acknowledge Alfanar Testing and Commissioning, Saudi Arabia for supporting to complete this research, especially thanks to Mr. Amer Abdullah Alajmi (GM, Engineering Service) and Mr. Abou Al Ez M. Hamed (Eastern Area Manager, AT\&C).

This is an Open Access article distributed under the terms of the Creative Commons Attribution License

\section{References}

1. Martin Naedele, Dacfey Dzung, and Michael Stanimirov. Network Security for Substation Automation Systems. Springer-Verlag, U. Voges (Ed.): SAFECOMP 2001, LNCS 2187, pp. 25-34, 2001.

2. Eltamaly, A.M. \& Abd Elghaffar, A.N. Modeling of distance protection logic for out of step condition in power system. Electrical Engineering Journal, Vol:100, 2018, https://doi.org/10.1007/s00202-017-0667-3

3. Ali M. Eltamaly, and Nasr A. Elghaffar, Amer. Techno-Economical Study of Using Nuclear Power Plants for Supporting Electrical Grid in Arabian Gulf. Technol Econ Smart Grids Sustain Energy Journal. DOI 10.1007/s40866-017-0031-8, 2017.

4. Adel A. Elbaset, Amer Nasr A. Elghaffar and Yehia Sayed. Smart Transmit Abnormal Condition in High Voltage Substation by SCADA System between Protection Equipment's and National Control Centre. 10th International Conference on Electrical Engineering, Military Technical College, EE039 - ICEENG 2016.

5. Cheng, X., Lee, W.J., Pan, X. Modernizing substation automation systems: adopting IEC standard 61850 for modeling and communication. IEEE Ind. Appl. Mag., 2017, 23, (1), pp. 42-49.

6. Mitalkumar G. Kanabar and Tarlochan S. Sidhu. Performance of IEC 61850-9-2 Process Bus and Corrective Measure for Digital Relaying. IEEE Transactions on Power Delivery, vol. 26, no. 2, 2011, doi:10.1109/TPWRD.2009.2038702

7. Bayindir R, Irmark E, Colak I, Bektas A. Development of a real time energy monitoring platform. Int $\mathrm{J}$ Electr Power Energy Syst 2011;33(1):137-46.

8. Razi Kazemi AA, Dehghanian P. A practical approach on optimal RTU placement in power distribution systems incorporating fuzzy sets theory. Int J Electric Power Energy Syst 2012; 37:31-42.

9. Ali Eltamaly, Yehia Sayed, Abou-Hashema El-Sayed and Amer Nasr A. Elghaffar. (2018). Multi-Control Module Static VAR Compensation Techniques for Enhancement of Power System Quality. Annals of Faculty Engineering Journal. ISSN: 2601-2332, Aug. 2018.

10. Ali Eltamaly, Yehia Sayed, Abou-Hashema M. El-Sayed, Amer Nasr A. Elghaffar. Adaptive static synchronous compensation techniques with the transmission system for optimum voltage control, Ain Shams Engineering Journal, (2019), https://doi.org/10.1016/j.asej.2019.06.002.

11. L.E. da Silva and D.V. Coury. A new methodology for real-time detection of attacks in IEC 61850-based systems. Electr. Power Syst. Res. (2016), http://dx.doi.org/10.1016/j.epsr.2016.08.022

12. Wei Pei. Wei Deng and Ziqi Shen. Operation of battery energy storage system using extensional information model based on IEC 61850 for micro-grids. IET Generation, Transmission \& Distribution, Vol: 10, PP: 849 - 861, 2014, DOI: 10.1049/ietgtd.2014.1123
13. Pradeep Y, Seshuraju P, Khaparde SA, Joshi RK. Flexsible open architecture design for power system control centres. Int J Electric Power Energy Syst 2011;33(4):976-82.

14. Shantanu Kumar, et al. Performance Analysis of Substation Automation Systems Architecture Based on IEC 61850. Australasian Universities Power Engineering Conference, AUPEC 2014, Curtin University, Perth, Australia, 2014, DOI: 10.1109/AUPEC.2014.6966532

15. Parth Desaia, Sharyu Mahale, Pooja Desai and Sunil Karam. Smart SCADA and Automation System in Power Plants. International Journal of Current Engineering and Technology, ISSN 2347 -5161, PP: 3484-3488, 2014.

16. Gajendra Kumar, Sunil Bhatt. Performance of A SCADA system for large distribution network transactions on power systems. Global Journal of Advance Engineering Technologies and Sciences ISSN: 2349-0292, PP: 47-51, 2015.

17. David Dolezilek. Case Study Examples of Interoperable Ethernet Communications Within Distribution, Transmission, and WideArea Control Systems. 2010 IEEE International Conference on Communications Workshops, DOI: 10.1109/ICCW.2010.5503918

18. Shi-Jaw Chen, Yi-Hsiang Wang, Chia-Hung Lin, Tung-Sheng Zhan, Rung-Fang Chang and Ya-Chin Chang. Using Multi-Vendor IEDs for IEC 61850 Interoperability and HMI-SCADA Applications. 2012 International Symposium on Computer, Consumer and Control, DOI: 10.1109/IS3C.2012.193.

19. N. Moreira et al. Cyber-security in substation automation systems. Renewable and Sustainable Energy Reviews 54 (2016) 1552-1562, 2016, http://dx.doi.org/10.1016/j.rser.2015.10.124

20. P. Rajagopal, et al. Effective utilization of SCADA for substation protection and control applications. 13th International Conference on Development in Power System Protection (DPSP), United Kingdom, pp. 1 - 5, March 2016.

21. B. Madonsela et al. Advances in Telecontrol and Remote Terminal Units (RTU) for Power Substations. IEEE Power Africa 2018 At: Cape Town, South Africa, 2018, DOI: 10.1109/PowerAfrica.2018.8521181

22. Soroush Shirali, Shahab Ensafi, Mahsa Naseri. RTU Hardware Design for SCADA Systems Using FPGA. 2010 International Conference on Computer Applications and Industrial Electronics (ICCAIE 2010), December 5-7, 2010, Kuala Lumpur, Malaysia, DOI: 10.1109/ICCAIE.2010.5735058.

23. Xueyang Cheng, Wei-Jen Lee and Xianghua Pan. Modernizing Substation Automation Systems: Adopting IEC Standard 61850 for Modeling and Communication. IEEE Industry Applications, PP: 42 - 49, 2016, DOI: 10.1109/MIAS.2016.2600732.

24. L. Cristaldi, et al. The impact of Internet transmission on the uncertainty in the electric power quality estimation by means of a 
distributed measurement system, IEEE Trans. Instrum. Meas., vol. 52, no. 4, pp. 1073-1078, 2003.

25. Aurabind Pal and Roma Dash. A Paradigm Shift inSubstation Engineering: IEC 61850 Approach. SMART GRID Technologies, August 6-8, 2015, doi: 10.1016/j.protcy.2015.10.003

26. Yonghui $\mathrm{Yi}$, et al. An IEC 61850 Universal Gateway Based on Metadata Modeling. 2007 IEEE Power Engineering Society General Meeting. DOI: 10.1109/PES.2007.385889

27. Byong-Kwan Yoo, Seung-Ho Yang, Hyo-Sik Yang, Won-Yong Kim, Yu-SeokJeong, Byung-Moon Han and Kwang-Soo Jang. (2011). Communication Architecture of the IEC 61850-based Micro Grid System. Journal of Electrical Engineering \& Technology Vol. 6, No. 5, PP: 605 612, DOI: 10.5370/JEET.2011.6.5.605

28. Hao Zou, et al. Design and Implementation of Data Gateway Communication Protocol Based on XML. 2016 IEEE Advanced Information Management, Communicates, Electronic and Automation Control Conference (IMCEC), DOI: 10.1109/IMCEC.2016.7867324

29. Ali Eltamaly, Amer Nasr A. Elghaffar, Yehia Sayed and AbuHashema M. El-Sayed. Advanced Control Techniques for Enhance the Power System Stability. Insite Energy Science Journal, PiscoMed Publishing Pte. Ltd. Singapore, 2018.

30. C. M. De Dominicis, P. Ferrari, A. Flammini and S. Rinaldi. On the use of IEEE1588 in Existing IEC61850 based SASs: Current Behavior and Future Challenges. IEEE Transactions on Instrumentation and Measurement (Volume: 60, 2011), PP: $3070-$ 3081, DOI: 10.1109/TIM.2011.2158159.

31. Xueyang Cheng, Wei-Jen Lee and Xianghua. Electrical substation automation system modernization through the adoption of IEC 61850. IEEE/IAS 51st Industrial \& Commercial Power Systems Technical Conference, ISSN: 2158-4893, 2015, DOI: 10.1109/ICPS.2015.7266445.

32. Neil Higgins, Valeriy Vya., Nirmal-Kumar C. Nair and Karlheinz Schwarz. Distributed Power System Automation with IEC 61850, IEC 61499, and Intelligent Control. IEEE Transactions on Systems, Man, and Cybernetics, Part C, Vol: 41, PP:81-92, 2010, DOI: $10.1109 /$ TSMCC.2010.2046322.

33. Christoph Brunner. Will IEEE 1588 Finally Leverage the lEC 61850 Process Bus?. 10th IET International Conference on Developments in Power System Protection (DPSP 2010). Managing the Change, Manchester, UK, DOI: 10.1049/cp.2010.0228

34. J. M.Ghee, M. Goraj, Smart High Voltage Substation based on IEC 61850 Process Bus and IEEE 1588 Time Synchronization, Smart Grid Communications (Smart Grid Comm), 2010 First IEEE International Conference, 2010 IEEE, DOI: 10.1109/SMARTGRID.2010.5622092.

35. Mohd Asim Aftab, Saeed Roostaee, S.M. Suhail Hussain, Ikbal Ali, Mini S. Thomas, Shabana Mehfuz. Performance evaluation of IEC 61850 GOOSE based inter-substation communication for accelerated distance protection scheme. IET Gener. Transm. Distrib., 2018, Vol. 12 Iss. 18, pp. 4089-4098.

36. Hawrylak P.J., Nivethan J., Papa M. Automating Electric Substations Using IEC 61850. In: Pappu V., Carvalho M., Pardalos P. (eds) Optimization and Security Challenges in Smart Power Grids. Energy Systems. Springer, Berlin, Heidelberg, 2013, DOI: https://doi.org/10.1007/978-3-642-38134-8_6

37. Salvatore Cavalieri, Alessio Regalbuto. Integration of IEC 61850 SCL and OPC UA to improve interoperability in Smart Grid environment, Computer Standards \& Interfaces, 2015, Doi: 10.1016/j.csi.2015.10.00

38. Adel A. Elbaset, Amer Nasr A. Elghaffar, et.al. The Optimum Tests For High Voltage SF6 Circuit Breaker In The New Substation Before Energize with The National Grid. International Journal of Technology Enhancements and Emerging Engineering Research, VOL 3, ISSUE 11, ISSN 2347-4289, 2015.

39. M. Antonijević, S. Sučić and H. Keserica. Augmented reality for substation automation by utilizing IEC 61850 communication. 39th International Convention on Information and Communication Technology, Electronics and Microelectronics (MIPRO) - PP: 316 - 320, 2016, DOI: 10.1109/MIPRO.2016.7522159.

40. Vivek Kumar Singh, A.S. Thoke and Chandra Prakash Awasthi. Procedures for testing control and protection scheme based on GOOSE messages-methodology and constraints from engineering perspective. IEEE International Conference on Power Electronics, Intelligent Control and Energy Systems, 2016, DOI: 10.1109/ICPEICES.2016.7853201.
41. L.E. da Silva, D.V. Coury, A new methodology for real-time detection of attacks in IEC 61850-based systems, Electr. Power Syst. Res. (2016), http://dx.doi.org/10.1016/j.epsr.2016.08.022

42. Lauri Kumpulainen, Anssi Jäntti and Juha Rintala. Benefits and performance of IEC 61850 Generic Object-Oriented Substation Event-based communication in arc protection. IET Generation, Transmission \& Distribution (Volume: 11), PP: 456 - 463, 2016, ISSN: 1751-8695, DOI: 10.1049/iet-gtd.2016.1003.

43. Micaela Caserza Magro, Paolo Pinceti, Luca Rocca and Giorgio Rossi. Safety related functions with IEC 61850 GOOSE messaging. Electrical Power and Energy Systems journal, V: 104, PP: 515-525, 2019, https://doi.org/10.1016/j.ijepes.2018.07.033.

44. Ikbal Ali, S. M. Suhail Hussain, Ashok Tak and Taha and Selim Ustun. Communication Modeling for Differential Protection in IEC 61850 Based Substations. IEEE Transactions on Industry Applications, 2017, DOI 10.1109/TIA.2017.2740301

45. Adel A. Elbaset, Yehia Sayed and Amer Nasr A. Elghaffar. Treatment Effect of EMF on The Protection IEDs in HV Substations. Nineteenth International Middle East Power Systems $\begin{array}{lll}\text { Conference } & \text { (MEPCON). }\end{array}$ 10.1109/MEPCON.2017.8301245

46. S. Kumar, N Das and S. Islam. Performance evaluation of a process bus architecture in a zone substation based on IEC 61850-9-2. 2015 IEEE PES Asia-Pacific Power and Energy Engineering Conference (APPEEC), DOI: 10.1109/APPEEC.2015.7381017

47. S. Kumar, N Das and S. Islam. Implementing PRP and HSR Schemes in a HV Substation based on IEC62439-3. 2018 Condition $\begin{array}{lll}\text { Monitoring and Diagnosis } & \end{array}$ DOI: $10.1109 / \mathrm{CMD} .2018 .8535663$

48. Hebat allah Mohamed Sharaf, H.H. Zein eldin, Doaa Khalil Ibrahim and Essam EL-Din Abou EL-Zahab. A proposed coordination strategy for meshed distribution systems with DG considering userdefined characteristics of directional inverse time overcurrent relays. Electrical Power and Energy Systems 65, PP: 49-58, 2014, DOI: 10.1016/j.ijepes.2014.09.028.

49. Adel A. Elbaset, Yehia Sayed and Amer Nasr A. Elghaffar. Mathematical calculation of electromagnetic field in high voltage substations to treatment its effect on the protective equipments. ANNALS of Faculty Engineering Hunedoara - International Journal of Engineering Tome, XIV [2016] - Fascicule 4, ISSN: 1584-2665.

50. J. Horalek, J. Matyska and V. Sobeslav. Communication Protocols in Substation Automation and IEC 61850 based proposal. 2013 IEEE 14th International Symposium on Computational Intelligence and Informatics (CINTI), 2013, PP: $321-326$, DOI: 10.1109/CINTI.2013.6705214

51. S. Kumar, N Das and S. Islam. Protection Redundancy in a Digital Network within a High Voltage Utility Substation based on IEC 62439-3. Australian Protection Symposium 1 Melbourne, 16-17 August 2016.

52. Mingyu Han, Hao Guo, Peter Crossley. EEE 1588 time synchronisation performance for IEC 61850 transmission substations. Electrical Power and Energy Systems, 107, pp: 264:272. 2019, https://doi.org/10.1016/j.ijepes.2018.11.036

53. N. H. Ali and M.M. Eissa. Accelerating the protection schemes through IEC 61850 protocols. Electrical Power and Energy Systems, 102, pp: 189: 200. 2018, https://doi.org/10.1016/j.ijepes.2018.04.035

54. David M. E. Ingram, Pascal Schaub, Richard R. Taylor and Duncan A. Campbell. System-Level Tests of Transformer Differential Protection Using an IEC 61850 Process Bus. IEEE Transactions on Power Delivery, 2013, Doi:10.1109/TPWRD.2013.2291789

55. Wei Pei. et al. Operation of battery energy storage system using extensional information model based on IEC 61850 for microgrids. IET Generation, Transmission \& Distribution, V: 10, Issue: 4, PP: 849 - 861, 2014, DOI: 10.1049/iet-gtd.2014.1123

56. Jay Makhija. Comparison of protocols used in remote monitoring: DNP 3.0, IEC 870-5-101 \& Modbus. M.Tech. Credit Seminar Report, Electronics Systems Group, EE Dept, IIT Bombay, November 2003.

57. Ming-Ta Yang, Jyh-CherngGu, Po-Chun Lin, Yen-Lin Huang, Chun-Wei Huang, and Jin-Lung Guan. Interoperability and Performance Analysis of IEC61850 Based Substation Protection System. World Academy of Science, Engineering and Technology International Journal of Electrical, Computer, Energetic, Electronic and Communication Engineering- PP :497-505-2013, 2013.

58. Fan Zhang, Yongli Zhu1, Chunyu Yan, Jiangang Bi, HaijunXiong and Shuai Yuan. A Realization Method of Protocol Conversion 
Adel A. Elbaset, Yehia Sayed Mohamed and Amer Nasr A. Elghaffar/

Journal of Engineering Science and Technology Review 13 (2) (2020)1 - 12

Between Modbus and IEC 61850. Open Journal of Applied Sciences, PP: 18-23, 2013, doi:10.4236/ojapps.2013.32B004.

59. Marco Agustoni and Alessandro Mortara. A Calibration Setup for IEC 61850-9-2 Devices. IEEE Transactions on Instrumentation and Measurement, 2017, PP: 1-7, DOI: 10.1109/TIM.2017.2665938.

60. Markku Hyvarinen, Seppo Pettissalo and Petri Trygg. A comprehensive secondary substation monitoring system. Electricity Distribution - Part 1, 2009. CIRED 2009. 20th International Conference and Exhibition on, PP:8-11, DOI: 10.1049/cp.2009.0920
61. Ali Eltamaly and Amer Nasr A. Elghaffar, Yehia Sayed and AbouHashema M. El-Sayed. Mitigation Voltage Sag Using DVR with Power Distribution Networks for Enhancing the Power System Quality. IJEEAS Journal. ISSN: 2600 -7495, Vol.1 No.2. Oct. 2018.

62. S. Roostaee, R. Hooshmand and Mohammad Ataei. Substation Automation System Using IEC 61850. The 5th International Power Engineering and Optimization Conference (PEOCO2011), Shah Alam, Selangor, Malaysia, 2011. 